Prepared in cooperation with the

National Oceanic and Atmospheric Administration

\title{
Sun-illuminated sea floor topography of Quadrangle 12 in the Stellwagen Bank National Marine Sanctuary off Boston, Massachusetts
}

By Page C. Valentine, Tanya S. Unger, and Jessica L. Baker

Geologic Investigations Series Map I-2712

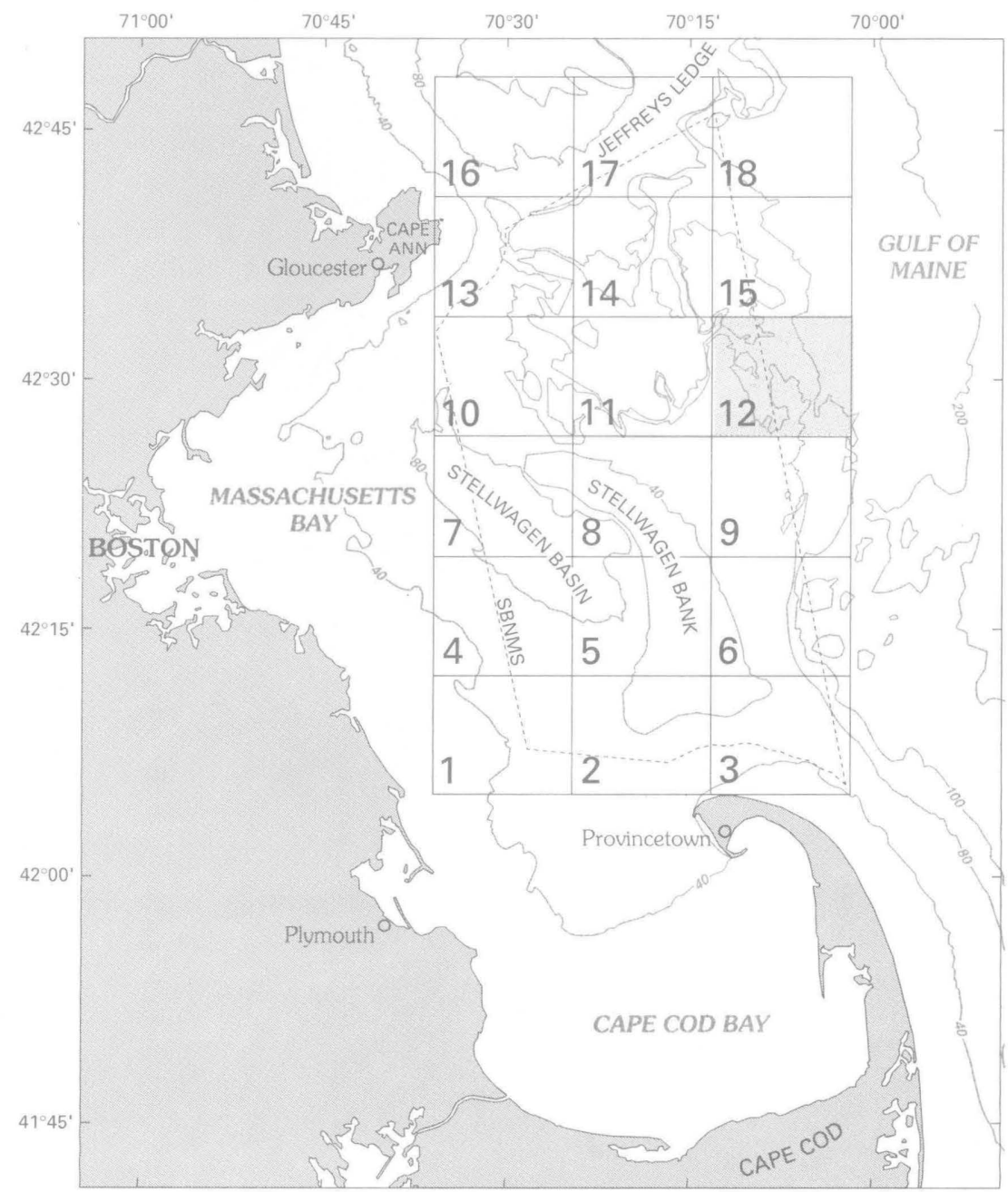

